\title{
Investment decision support for zero subsidy wind and solar - An optimization based simulation approach
}

\author{
Florian Rothenberg, Sebastian Braun \\ EU Carbon and Power Analytics \\ ICIS \\ Karlsruhe, Germany \\ florian.rothenberg@icis.com
}

\author{
Florian Zimmermann, Dogan Keles, Wolf Fichtner \\ Chair of Energy Economics (IIP) \\ Karlsruhe Institute of Technology, \\ Karlsruhe, Germany \\ florian.zimmermann@kit.edu
}

\begin{abstract}
In the past decade, variable renewable energy sources became increasingly competitive due to rapidly falling manufacturing costs. However, prices cannibalization could lead to limited market driven investments. In this paper, we present a method to use a dispatch model to find an investment decision that can account for country risk factors such as social acceptance as well as the fundamental factors that influence the power market such as existing capacities and fuel prices. Results show that Solar PV is more affected by price cannibalization and Spain has large unrealized potential for market driven Solar PV investments.
\end{abstract}

Index Terms-- Investment decisions, Electricity markets, Renewable Energy Sources, Optimization, Simulation.

\section{INTRODUCTION}

The costs of variable renewable energy sources (VRES) such as onshore and offshore wind and solar PV declined massively in the past years and are set to further shrink [1][2]. However, while VRES have become more and more competitive, their revenues face increasing uncertainty. The first reason for that is the likely end of risk minimizing renewable subsidy schemes such as fixed feed in tariffs. The trend in most EU member states already goes towards market driven subsidy schemes e.g. with competitive tenders [3]. These schemes leave VRES investors exposed to fluctuating market conditions, which is priced in by risk-averse investors [4]. Competing in a wholesale market, increased generation capacities from solar and wind decrease the price that can be "captured" on an energy-only market due to zero variable costs and the merit order effect [5]. Overall, the dilemma of decreasing revenues opens the question on how much investments in VRES can be expected in the increasingly coupled EU spot electricity markets in the case of fullmerchant investments in VRES. The methodology presented in this paper seeks to support the decision-making by presenting a method that maps the investment attractiveness of a technology in a specific wholesale market defined by the investor's internal rate of return (IRR) and hurdle rate to the overall market potential. This market potential is bounded by price cannibalization as well as the difference between the IRR and hurdle rate.

\section{INVESTMENT DECISION MAKING IN LIBERALIZED} POWER MARKETS

\section{A. Capital costs reflect investment risk}

From a capital providers' perspective, capital costs are the minimum rate of return in percent that they would expect to invest in a project, at least the capital costs of an investment must be covered.. Before carrying out an economic feasibility study of a power plant project, a company, therefore, has to determine its minimum return that is needed from an investment to cover both costs of equity and cost of debt. These capital costs shall also account for the risk associated with an investment. For investments in subsidy-free VRES these occur especially due to technology risk, social acceptance risk and revenue risk due to fluctuacting power prices. A commonly used metric in liberalized power markets are the weighted average cost of capital (WACC), which is the weighted average of the capital costs for debt and equity before or after taxes. The weights for debt and equity are set based on the financings tructure of the project. The WACC can include project specific risk factors and determines an investment threshold or hurdle rate and quantifies all risk factors relevant for power market investments. This also includes revenue risk occuring due to fluctuating fuel prices. Usually the metric is individual to an investor or company but are usually also specific to a area and technology and can be defined accordingly [6].

\section{B. The Internal rate of return can indicate attractiveness of market and technology}

There are multiple methods to assess the profitability of new power generation assets, which include the Net present value (NPV), the internal rate of return (IRR) and the levelized costs of electricity (LCOE). All these metrics are based on the principle of discounting all cash flows and expenditures related to a project. The factors used to calculate the metrics are equivalent. While for NPV and LCOE the investor's capital costs are hidden in the outcome, the 
advantage of the IRR is the direct link to the investors risk perception and capital costs represented by the hurdle rate. The hurdle rate can be described by the WACC, which we introduced before.

$$
\operatorname{add}_{\mathrm{t}+\mathrm{c}, \mathrm{a}}=\max \left(\frac{\mathrm{IRR}_{\mathrm{t}}-\mathrm{WACC} \mathrm{a}}{-\left(\mathrm{s}_{\mathrm{t}+\mathrm{c}, \mathrm{a}}\right)}, 0\right)
$$

add $=$ capacity addition

$\mathrm{t}=$ year of investment decision

$\mathrm{c}=$ project lead time

$\mathrm{a}=$ target market

\section{Renewable expansion}

Past research on the "Merit Order Effect" implied mainly an effect of VRES expansion on the profitability and investment decisions into conventional power sources as these are increasingly pushed out of the merit order[7]. Nevertheless, the effect of VRES has on its proprietary revenues is crucial. The variable and intermitted nature of wind and solar generation influences the prices VRES can receive on the wholesale market. In windy and sunny times, the additional power supply pushes electricity prices down. With an increasing share of renewable capacity, this "pricecannibalization" increases even more. The price cannibalization effect has been shown both by using historical data as well as using numerical power market models [5], [8]. Therefore, while investors can calculate the IRR of a VRES generation capacity project they need to face the risk of price cannibalizing when overall installed capacities expand.

Historic data shows, that there generally is a positive relationship between the observed IRR and the amount of capacity invested. Research shows a linear relationship between newly installed rooftop solar PV systems and the IRR in Germany 2004-2016. A linear regression model suggests that $879 \mathrm{MW}$ of capacity were added for each increase in the IRR by $1 \%$. The profitability in the meanwhile explained $65 \%$ of the variation in investments [9]. A limitation of this approach are, however, irrational behavior and the market growth. In an emerging market, the necessary infrastructure has to develop over time. For example, manufacturers of solar panels need to scale up their production in order to be able to serve the demand. Therefore, the amount of investments especially in the early years of a technology cannot fully reflect the internal rate of return. |

\section{Investing in everything that is profitable}

Thus, in a competitive and mature market, there should be no difference between the IRR of a new power plant project and the hurdle rate of an investor as the IRR exceeds the hurdle rate would present a profitable investment. Therefore, investors would decide to invest in the technology until the IRR equals the hurdle rate. Depending how mature the infrastructure for investments this reduction could happen faster or slower. After all, the amount of added capacity in a competitive market should be defined as

$$
s=\Delta \mathrm{IRR} / \Delta \text { Installed capacity }
$$

The function describes the rationale of investing everything that is profitable. In order to derive the function for a specific type of VRES in a liberalized market, we have to calculate $s$, which is defined as the change in the IRR when a marginal unit of capacity is added.

\section{Methodology}

In order to analyze how much the IRR changes when capacity is added, we use an electricity market dispatch model. In the case of this study, we use the HORIZON model [10] that is based on the THEMA power market model (TheMA) [11], This fundamental power market dispatchmodel reflects the price setting across 28 European power markets by in a linear program (LP) that minimizes the overall system costs under several constraints (cross-border flows, start-up costs, etc.). Flexible generation capacities, electricity demand as well as renewable feed-in profiles, are external input data.

The process of retrieving the sensitivity of the IRR of a VRES power plant in a market starts by adding a representative block of $1 \mathrm{MW}$ to the dispatch model. For the generation profiles we use 2016 ENTSO-E transparency data[12]. In this case, we choose to set the generation profile as a maximum profile and thereby allowing economic based curtailment in the case power prices go to negative. The representative blocks allow extracting the optimal behavior and economic characteristics of the plant for an investment period.

Further, we defined the investment characteristics of solar PV and onshore wind farms using standard assumptions for the capital expenditures (CAPEX), operating expenditures (OPEX) and economic lifetime that are shown in Table 1 and are based both on [13] for OPEX and lifetime and own cost component research.

\section{TABLE 1: INVESTMENT CHARACTERISTICS.}

\begin{tabular}{|l|l|l|}
\hline \multirow{2}{*}{ variable } & \multicolumn{2}{c|}{ generation type } \\
\cline { 2 - 3 } & Solar $\boldsymbol{P V}$ & Wind Onshore \\
\hline CAPEX $[€ / \mathrm{MW}]$ & 660.000 & 1.200 .000 \\
\hline OPEX $[€ / \mathrm{MW} / \mathrm{p} . \mathrm{a}]$. & 16500 & 30000 \\
\hline Economic lifetime & 25 years & 25 years \\
\hline
\end{tabular}

Figure 2 overall shows the algorithm in which we ran the dispatch model iteratively for different capacities until a maximum capacity of $X$. In between the profitability of the generation asset by calculating the revenue $1 \mathrm{MW}$ of a VRES power plant is extracted for the respective market in which it operates. Using the investment parameters described in Table 1, IRR is calculated. 
As we are looking for the general sensitivity of the IRR under an increase in capacity, we run the IRR not only until a hurdle rate or to a level of zero, but also beyond. The revenue from the power market is influenced by the costs of energy commodities such as natural gas and emission allowance prices as well as all factors defined in the HORIZON model (Hydro inflow, transmission capacities i.e.). Depending on the assumption made for a power market in a target year $t$ and the technology-based costs, the starting IRR can be higher or lower.

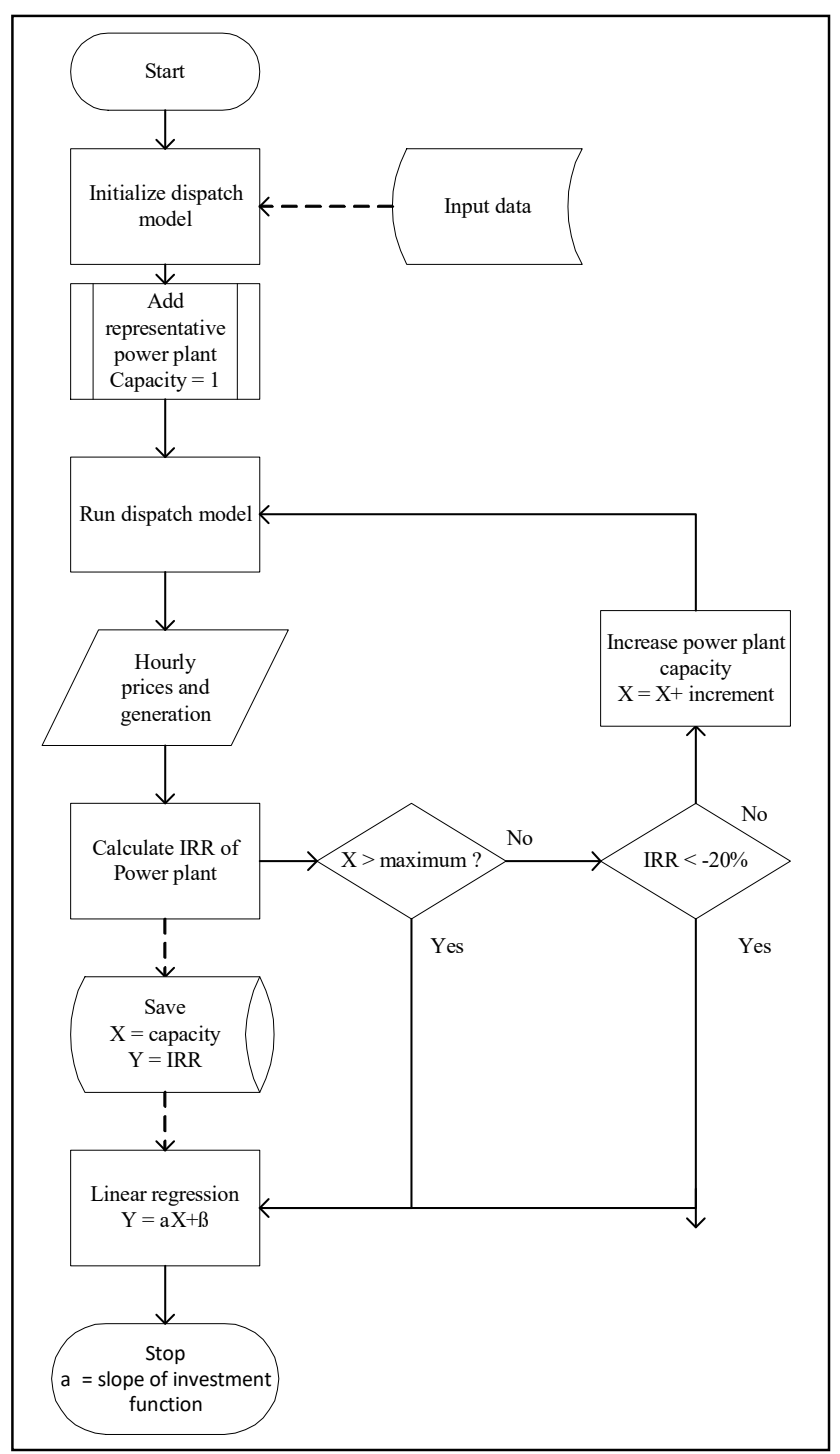

Figure 2: Algorithm to calculate the slope of the investment function defined in (2).

Assuming investors would i.e. observe a higher IRR as fuel prices or input parameters, such as the CAPEX, change over time, the IRR could be generally higher and therefore, not the whole range of IRR sensitivity would be calculated. However, as Figure 1 shows and as we mentioned before, the main area of interest is the sensitivity of the IRR described by (2).

To calculate the sensitivity (2) or slope of the investment function, in a last step we use the set of capacities $x$ as well as the set of corresponding IRRs and perform a simple linear regression. The slope of the regression we define as the sensitivity (2) we can use in the investment function (1).

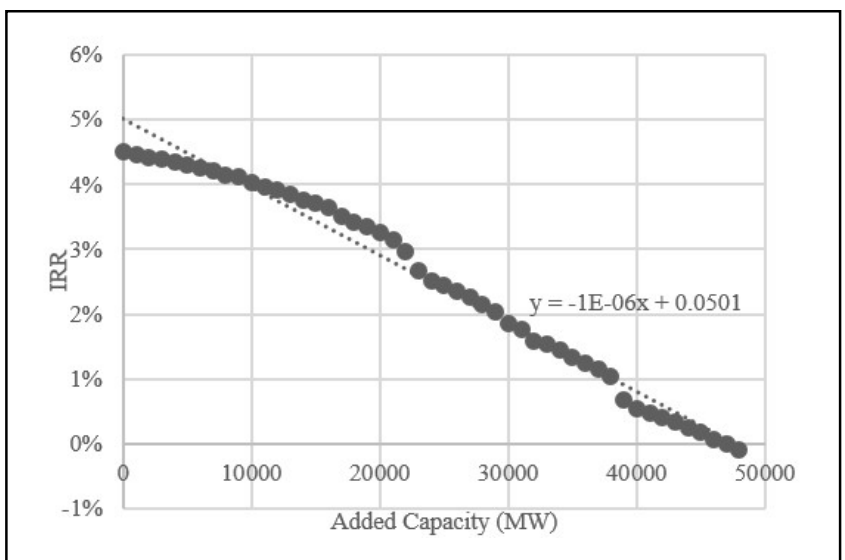

Figure 1: Linear regression of simulation results

In order to demonstrate the methodology described in Figure 2 we perform the analysis for solar PV and onshore wind in the French, German and Spanish power market in the year 2020. The capacities are assumed to be on end of 2019 levels. The same holds true for fuel prices where we use the $\mathrm{Cal}$ ' 20 forwards prices for fuels and demand from ENTSO-E [12]. Further, we limit the resolution of the dispatch model to 24 representative hours for each week of the year in order to reduce the computation time.

\section{RESULTS}

\section{A. Sensitivity Analysis}

Using the approach described, we optimize the power markets France, Germany and Spain for wind onshore and solar PV iteratively and save the IRR in between. The analysis is performed ceteris paribus, meaning that we change the capacity in one country after another and hold all other factors constant. The IRR depending on the added wind onshore or PV capacity is displayed in Figure 3 for the year 2020. The starting point at one MW added capacity already reveals the profitability of an MW of added capacity of the respective technology in the respective power market, assuming ceteris paribus, therefore, the conditions defined in Section III will remain constant. Increasing the added capacity in $1000 \mathrm{MW}$ steps we observe a steady drop in the IRR in the model. The reaction of the IRR is unique to the power markets and the generation profile. In the Spanish power market, we see that under our set of assumptions we would observe a generally high profitability of Solar PV with an IRR of $15.9 \%$. This IRR would drop relatively stable for 
each additional $1000 \mathrm{MW}$ of generation capacity added and would reach $13.7 \%$ in a case of $10 \mathrm{GW}$ of added capacity. At a capacity addition of $34 \mathrm{GW}$, the IRR reaches zero meaning that at this point the NPV for a solar PV project that adds an additional MW of capacity would only be larger than zero in case the capital costs would be smaller than zero. Therefore, the project will not be profitable.

The results show that the decline in IRR for onshore wind generation is generally flatter than for solar PV. The IRR of onshore wind reacts slower to further capacity additions than solar. This phenomenon of a stronger cannibalization effect can be explained - among other things by the fact that solar PV generation is concentrated during daylight hours, while onshore wind generates independently of this as well as the higher wind output during the highdemand winter months.

\section{B. Regression results}

\section{TABLE 2: REGRESSION RESULTS}

\begin{tabular}{|l|l|l|l|}
\hline \multirow{2}{*}{ Market/Technology } & \multicolumn{3}{|c|}{ Regression parameter } \\
\cline { 2 - 4 } & intercept & coefficient & $\boldsymbol{R}^{\mathbf{2}}$ \\
\hline Germany/Solar PV & 0.04 & $-2.59 \mathrm{E}-06$ & 0.93 \\
\hline $\begin{array}{l}\text { Germany/Wind } \\
\text { Onshore }\end{array}$ & 0.06 & $-1.29 \mathrm{E}-06$ & 0.98 \\
\hline Spain/Solar PV & 0.17 & $-4.45 \mathrm{E}-06$ & 0.99 \\
\hline Spain/Wind Onshore & 0.10 & $-2.92 \mathrm{E}-06$ & 0.96 \\
\hline France/Solar PV & 0.06 & $-3.59 \mathrm{E}-06$ & 0.91 \\
\hline France/Wind Onshore & 0.03 & $-9.93 \mathrm{E}-07$ & 0.93 \\
\hline
\end{tabular}

Using the results of the sensitivity analysis from Section A, a linear regression is performed in order to maintain the slope of the IRR as a function of the capacity increase. The results in Table 2 show, that most of the variation in the IRR can be explained by the addition of extra capacity. In all cases the $\mathrm{R}^{2}$ is larger than 0.9 . The coefficient for Germany i.e. implies that in the current power system for each $1000 \mathrm{MW}$ of solar PV the IRR of the next MW would drop by 0.259 percentage points while for PV in Spain the IRR would decrease by 0.445 percentage points.

\section{Investment functions}

Using the formula (1) as well as the regression results in Table 2 and the findings of [6] we can compute the investment functions illustrated in Figure 4 were investments start at the WACC and develop according to the calculated sensitivity. Studies [6] find significant differences in the WACC for onshore wind projects among European countries that can be in inter alia explained by different costs of debt that vary between $1.8 \%$ in Germany and $12.6 \%$ in Greece in 2014. The study is outdated and accounts for risk minimizing subsidy schemes. It is used as an example here to illustrate the significance of risk factors on renewable energy investments. The function illustrated in Figure 4 shows that in Germany if the IRR of the average investors is at $6 \%, 15.5$ $\mathrm{GW}$ of onshore wind could be installed so that the average investor would still have returns marginally above their WACC. At the same time in Spain, the IRR would have to be higher at around $15 \%$ to install the same amount of wind generation capacity. Further, it can be seen that onshore wind energy in France is less affected by price cannibalization and therefore more could be invested as soon as the IRR passes the WACC.

\section{CONCLUSION AND DisCUSSION}

The methodology presented in this paper can be used to estimate the overall potential for subsidy-free VRES capacity investments and support investors in estimating their risk of price cannibalization. If an average PV plant in Spain in 2020 has an IRR of $15 \%$ the market could accommodate $11.26 \mathrm{GW}$ of additional PV capacity assuming an average hurdle rate of $10 \%$. In a competitive market with no other investment alternatives capacity would be added until the hurdle rate is reached and therefore we would finally see $11.26 \mathrm{GW}$ of additional PV capacity. To accommodate more capacity,

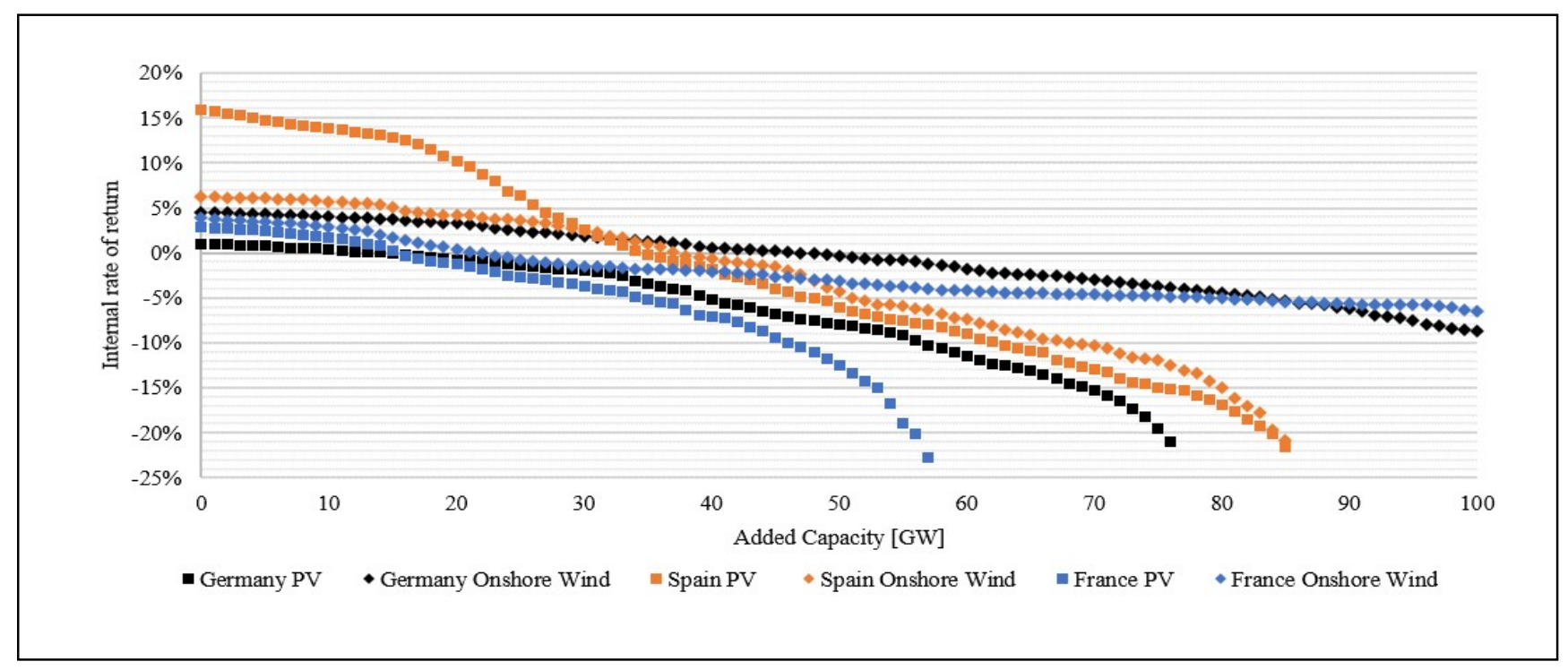

Figure 3: Sensitivity results of onshore wind and PV for the year 2020 in Germany, Spain and France

978-1-7281-6919-4/20/\$31.00@2020 IEEE 
either the costs for PV modules would have to fall further or power prices would need to rise driven i.e. by the price of emission allowances, fuel costs or demand.

The approach described in this paper has several advantages that include the use of a dispatch model that can account for all power market variables such as interconnectors, the flexibility of existing generation assets and therefore accounts for the possibility of VRES investors to push fossil generation out of the market. On the other hand, it directly includes risk factors that are not modelled in the dispatch model as well as the capital market. Both factors can be represented by the WACC that can be estimated as done in prior research [6]. This also includes the risk of fluctuating fuel and $\mathrm{CO} 2$ prices as the revenue risk is implicitly modelled in the WACC.

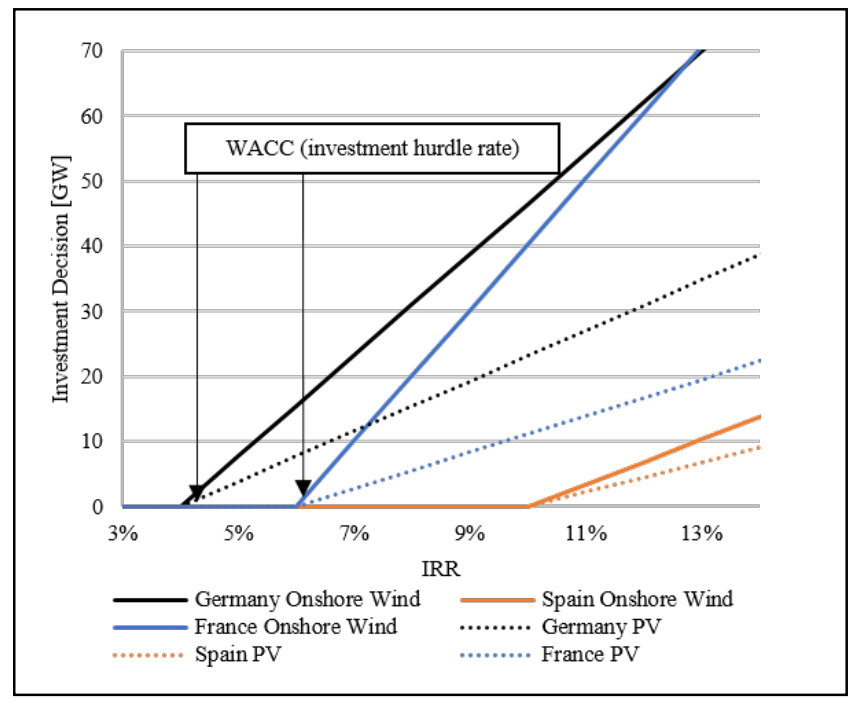

Figure 4: Investment function for solar PV and wind onshore in Spain, France and Germany

Limitations are the ceteris paribus nature of investment decisions and power market assumptions. This means that i.e. investments in other VRES generation capacities or in other interconnected markets are ignored. As France might see extra PV capacity as well and fuel prices can change, the capacity that would finally be installed in Spain could be lower or higher. Further, the investment function assumes that the market is perfectly competitive and every investor uses all possible investment opportunities that yield above the WACC. Another limitation is that the natural and social acceptance boundaries such as available sites for VRES projects is not reflected. Even an IRR of $12 \%$ for an average wind onshore project would not lead to $70 \mathrm{GW}$ of additional wind onshore capacity in Germany, as profitable sites become scarce.

While the investment functions can be used to generally, estimate the market potential of subsidy free investments and identify needs for additional storage solutions or subsidies it is not suited to predict the future power market by applying the function to all markets in
Europe at the same time, as this would lead to overinvestment. Therefore, an idea for further research would be to use investment curves in predictive simulations of the future power system were adjusted investment curves are applied year-by-year and fuel prices, investments, demand and conventional generation capacities change between the years gradually.

\section{REFERENCES}

[1] E. Vartiainen, G. Masson, C. Breyer, D. Moser, and E. R. Medina, "Impact of weighted average cost of capital, capital expenditure, and other parameters on future utility-scale PV levelised cost of electricity," Prog. Photovoltaics Res. Appl., p. pip.3189, 2019.

[2] R. Wiser et al., "Expert elicitation survey on future wind energy costs," Nat. Energy, vol. 1, no. 10, Oct. 2016.

[3] ICIS, "ICIS RES Support Database," 2020. [Online]. Available: https://analytics.icis.com/eu-powerlongterm/eu/post-subsidy-res-support/\#tab:SF.

[Accessed: 14-Jan-2020].

[4] S. Salm, "The investor-specific price of renewable energy project risk - A choice experiment with incumbent utilities and institutional investors," Renewable and Sustainable Energy Reviews. 2018.

[5] L. Hirth, "The market value of variable renewables: The effect of solar wind power variability on their relative price," Energy Econ., vol. 38, pp. 218-236, Jul. 2013.

[6] P. Noothout et al., "The impact of risks in renewable energy investments and the role of smart policies ," 2016.

[7] C. Kong, C. M. Pollitt, and R. Cruise, "Can Wholesale Electricity Prices Support \&quot;SubsidyFree Generation Investment in Europe\&quot;," 2019.

[8] J. López Prol, K. W. Steininger, and D. Zilberman, "The cannibalization effect of wind and solar in the California wholesale electricity market," Energy Econ., 2019.

[9] T. H. Do and H. Clemens, "Innovation of price adjustment mechanisms to support investment in solar power in Germany," E3S Web Conf., vol. 64, 2018.

[10] ICIS, "ICIS Long-term Power Analytics | ICIS." [Online]. Available: https://www.icis.com/explore/services/analytics/powe ranalytics/. [Accessed: 13-Jun-2020].

[11] THEMA, "Power market model - Thema." [Online]. Available: $\quad$ http://thema.no/price-forecasts-andmodels/power-market-model/?lang=en. [Accessed: 13-Jun-2020].

[12] ENTSOE, "ENTSO-E Transparency Platform." [Online]. Available: https://transparency.entsoe.eu/. [Accessed: 13-Jun-2020].

[13] C. Kost and T. Schlegl, "Stromentstehungskosten von erneuerbaren Energien," 2018. 